\title{
Unintended effects of statins in men and women in England and Wales: population based cohort study using the QResearch database
}

\author{
Julia Hippisley-Cox, professor of clinical epidemiology and general practice, Carol Coupland, associate \\ professor in medical statistics
}

Division of Primary Care, University Park, Nottingham NG2 7RD Correspondence to: J Hippisley-Cox julia.hippisley-cox@ntlworld.com

Cite this as: $B M J$ 2010;340:c2197 doi:10.1136/bmj.c2197

\section{ABSTRACT}

Objective To quantify the unintended effects of statins according to type, dose, and duration of use.

Design Prospective open cohort study using routinely collected data.

Setting 368 general practices in England and Wales supplying data to the QResearch database.

Participants 2004692 patients aged $30-84$ years of whom 225922 (10.7\%) were new users of statins: 159790 (70.7\%) were prescribed simvastatin, 50328 (22.3\%) atorvastatin, 8103 (3.6\%) pravastatin, 4497 (1.9\%) rosuvastatin, and 3204 (1.4\%) fluvastatin.

Methods Cox proportional hazards models were used to estimate effects of statin type, dose, and duration of use. The number needed to treat (NNT) or number needed to harm (NNH) were calculated and numbers of additional or fewer cases estimated for 10000 treated patients.

Main outcome measure First recorded occurrence of cardiovascular disease, moderate or serious myopathic events, moderate or serious liver dysfunction, acute renal failure, venous thromboembolism, Parkinson's disease, dementia, rheumatoid arthritis, cataract, osteoporotic fracture, gastric cancer, oesophageal cancer, colon cancer, lung cancer, melanoma, renal cancer, breast cancer, or prostate cancer.

Results Individual statins were not significantly associated with risk of Parkinson's disease, rheumatoid arthritis, venous thromboembolism, dementia, osteoporotic fracture, gastric cancer, colon cancer, lung cancer, melanoma, renal cancer, breast cancer, or prostate cancer. Statin use was associated with decreased risks of oesophageal cancer but increased risks of moderate or serious liver dysfunction, acute renal failure, moderate or serious myopathy, and cataract. Adverse effects were similar across statin types for each outcome except liver dysfunction where risks were highest for fluvastatin. A dose-response effect was apparent for acute renal failure and liver dysfunction. All increased risks persisted during treatment and were highest in the first year. After stopping treatment the risk of cataract returned to normal within a year in men and women. Risk of oesophageal cancer returned to normal within a year in women and within 1-3 years in men. Risk of acute renal failure returned to normal within 1-3 years in men and women, and liver dysfunction within 1-3 years in women and from three years in men. Based on the $20 \%$ threshold for cardiovascular risk, for women the NNT with any statin to prevent one case of cardiovascular disease over five years was 37 (95\% confidence interval 27 to 64 ) and for oesophageal cancer was 1266 (850 to 3460) and for men the respective values were 33 (24 to 57) and 1082 (711 to 2807). In women the NNH for an additional case of acute renal failure over five years was 434 (284 to 783), of moderate or severe myopathy was 259 (186 to 375), of moderate or severe liver dysfunction was 136 (109 to 175), and of cataract was 33 (28 to 38). Overall, the NNHs and NNTs for men were similar to those for women, except for myopathy where the NNH was 91 (74 to 112).

Conclusions Claims of unintended benefits of statins, except for oesophageal cancer, remain unsubstantiated, although potential adverse effects at population level were confirmed and quantified. Further studies are needed to develop utilities to individualise the risks so that patients at highest risk of adverse events can be monitored closely.

\section{INTRODUCTION}

Cardiovascular disease is the leading cause of premature death and a major cause of disability in the United Kingdom. ${ }^{1}$ Some meta-analyses and national policies support the use of statins to reduce the risk of cardiovascular disease among high risk patients. ${ }^{2-5}$ Validated risk prediction algorithms, such as QRISK2, are used to identify high risk patients most likely to benefit from interventions, including statins. ${ }^{67}$ Given that statins are already among the most widely prescribed medicines and that their use is likely to continue to increase, both their intended and their unintended effects and how these vary by type, dose, and duration of use need to be quantified in large representative populations. This information can then be used to inform policy and clinical practice by supplementing information from metaanalyses of clinical trials, which tend to lack sufficient detail, duration of follow-up, or sufficient power to make some of the relevant comparisons. ${ }^{2589}$ Also, meta-analyses can be subject to selection bias as trial 
Table 1| Baseline characteristics of study population of new users and non-users of statins. Values are numbers (percentages) unless stated otherwise

\begin{tabular}{|c|c|c|}
\hline Characteristics & $\begin{array}{c}\text { New users } \\
(n=225922)\end{array}$ & $\begin{array}{c}\text { Non-users } \\
(\mathrm{n}=1 \mathrm{778} 770)\end{array}$ \\
\hline Women & $104774(46.4)$ & $909423(51.1)$ \\
\hline Men & $121148(53.6)$ & $869347(48.9)$ \\
\hline \multicolumn{3}{|l|}{ Ethnicity: } \\
\hline Recorded & $121355(53.7)$ & $569466(32.0)$ \\
\hline White or not stated & $215077(95.2)$ & $1699991(95.6)$ \\
\hline Indian & $2861(1.3)$ & $13398(0.8)$ \\
\hline Pakistani & $1658(0.7)$ & $7562(0.4)$ \\
\hline Bangladeshi & $679(0.3)$ & $3226(0.2)$ \\
\hline Other Asian & $759(0.3)$ & $7321(0.4)$ \\
\hline Caribbean & $1788(0.8)$ & $9853(0.6)$ \\
\hline Black African & $834(0.4)$ & $15358(0.9)$ \\
\hline Chinese & $316(0.1)$ & $4015(0.2)$ \\
\hline Other ethnic group & $1950(0.9)$ & $18046(1.0)$ \\
\hline Mean (SD) age (years) & $57.2(11.7)$ & $44.4(13.7)$ \\
\hline Mean (SD) Townsend score & $-0.5(3.3)$ & $-0.3(3.4)$ \\
\hline Mean (SD) systolic blood pressure $(\mathrm{mm} \mathrm{Hg})$ & $141.1(19.1)$ & $129.9(19.1)$ \\
\hline \multicolumn{3}{|l|}{ Liver function test: } \\
\hline Recorded at baseline or before statins & $131354(58.1)$ & $162207(9.1)$ \\
\hline Recorded at follow-up & $193586(85.7)$ & $594750(33.4)$ \\
\hline \multicolumn{3}{|l|}{ Creatine kinase concentration: } \\
\hline Recorded at baseline or before statins & $15724(7.0)$ & $8642(0.5)$ \\
\hline Recorded at follow-up & $62706(27.8)$ & $43333(2.4)$ \\
\hline Body mass index recorded & 207644 (91.9) & $1341863(75.4)$ \\
\hline Mean (SD) body mass index & $28.3(4.9)$ & $26(4.6)$ \\
\hline Smoking status recorded & $224982(99.6)$ & $1615527(90.8)$ \\
\hline Body mass index and smoking status recorded & 207494 (91.8) & $1330320(74.8)$ \\
\hline Non-smoker & $109406(48.4)$ & $912149(51.3)$ \\
\hline Former smoker & $74277(32.9)$ & $285271(16.0)$ \\
\hline \multicolumn{3}{|l|}{ Current smoker: } \\
\hline Amount not recorded & $2286(1.01)$ & $55859(3.1)$ \\
\hline Light & $14447(6.4)$ & $116035(6.5)$ \\
\hline Moderate & $13880(6.1)$ & $142469(8.0)$ \\
\hline Heavy & $10686(4.7)$ & $103744(5.8)$ \\
\hline \multicolumn{3}{|l|}{ Comorbidities: } \\
\hline Atrial fibrillation & $11656(5.2)$ & $13730(0.8)$ \\
\hline Congestive cardiac failure & $7457(3.3)$ & $9026(0.5)$ \\
\hline Cardiovascular disease & $56943(25.2)$ & $31038(1.7)$ \\
\hline Peripheral vascular disease & $8801(3.9)$ & $12656(0.7)$ \\
\hline Treated hypertension* & $97782(43.3)$ & $106582(6.0)$ \\
\hline Chronic kidney disease stage $3 \mathrm{~b}+$ & $18768(8.3)$ & $17114(1.0)$ \\
\hline Type 1 diabetes & $2843(1.3)$ & $2633(0.2)$ \\
\hline Type 2 diabetes & $47703(21.1)$ & $18243(1.0)$ \\
\hline Endocrine disorders & $2749(1.2)$ & $9347(0.5)$ \\
\hline Malabsorption & $2156(1.0)$ & $11079(0.6)$ \\
\hline Rheumatoid arthritis & $3652(1.6)$ & $11762(0.7)$ \\
\hline Systemic lupus erythematosus & $264(0.1)$ & $1070(0.1)$ \\
\hline Asthma & $23307(10.3)$ & $139485(7.8)$ \\
\hline Falls & $10333(4.6)$ & $21805(1.2)$ \\
\hline Endocrine disorders & $2749(1.2)$ & $9347(0.5)$ \\
\hline Any cancer & $10727(4.8)$ & $32883(1.9)$ \\
\hline Hypothyroidism & $12378(5.5)$ & $30357(1.7)$ \\
\hline Chronic liver disease & $1016(0.5)$ & $3966(0.2)$ \\
\hline Colorectal polyps & $1215(0.5)$ & $1989(0.1)$ \\
\hline Family history of breast cancer (women only) & $3492(1.6)$ & $40519(2.3)$ \\
\hline Benign breast disease (women only) & $4343(1.9)$ & $32187(1.8)$ \\
\hline \multicolumn{3}{|l|}{ Prescribed drugs: } \\
\hline Corticosteroids & $13868(6.1)$ & $44517(2.5)$ \\
\hline Selective serotonin reuptake inhibitors & $16614(7.4)$ & $97712(5.5)$ \\
\hline Tricyclic antidepressants & $18469(8.2)$ & $69674(3.9)$ \\
\hline Depression & $13487(6.0)$ & $71557(4.0)$ \\
\hline Hormone replacement therapy & $5343(2.4)$ & $63972(3.6)$ \\
\hline Oral contraceptives & $303(0.1)$ & $72334(4.1)$ \\
\hline Non-steroidal anti-inflammatory drugs (including aspirin) & $125127(55.4)$ & $362589(20.4)$ \\
\hline Antipsychotic drugs & $10955(4.9)$ & $42683(2.4)$ \\
\hline
\end{tabular}

*Composite variable that includes recorded diagnosis of hypertension and treatment, which could include angiotensin converting enzyme inhibitors, angiotensin receptor blockers, aldosterone, $\beta$ blockers, thiazides, or calcium channel blockers. patients tend to be predominantly white, younger, and more healthy than real world populations, thus limiting generalisability and external validity. ${ }^{8}$

We carried out a large population based study to examine a range of clinical outcomes that have been found to be positively or negatively associated with statin use, including moderate or serious myopathic events, ${ }^{10-13}$ Parkinson's disease, ${ }^{14}$ dementia, ${ }^{1516}$ liver dysfunction,${ }^{8917}$ venous thromboembolism, ${ }^{18}$ rheumatoid arthritis, ${ }^{19}$ cataract, ${ }^{20}$ common cancers, ${ }^{921-24}$ and osteoporotic fracture. ${ }^{25-27}$ We also included acute renal failure as an outcome because of concerns published both in The Lance ${ }^{8}$ and on the Food and Drug Administration website, ${ }^{29}$ together with reports of proteinuria in patients prescribed rosuvastatin. ${ }^{30}$

\section{METHODS}

We carried out a prospective cohort study in a large population of primary care patients using version 24 of the general practice research database, QResearch. All practices in England and Wales that had been using the computer based Egton Medical Information System (EMIS) for at least a year were included. Two thirds of the practices were randomly allocated to the study dataset and one third was retained for a subsequent study. We identified an open cohort of patients aged 30-84 years from those registered with the practices between 1 January 2002 and 30 June 2008. We excluded patients without a postcode related Townsend score (about $4 \%$ of the population) and those who had been prescribed statins before, or were current users on, the date the study started. Entry to the cohort was the latest of the date the study started, 12 months after the patient registered with the practice, or, for new users of statins, the date of their first prescription. We censored patients at the earliest date of the diagnosis of interest, death, deregistration with the practice, last upload of computerised data, or the date the study ended (31 December 2008).

\section{Clinical outcomes}

We examined several outcomes, identified from Read codes recorded in the patients' electronic records (codes available from authors on request): acute renal failure $^{2830}$; venous thromboembolism ${ }^{18}$; Parkinson's disease $^{14} ;$ dementia ${ }^{1516} ;$ rheumatoid arthritis ${ }^{19}$; cataract $^{20}$; osteoporotic fracture (spine, hip, or wrist); common cancers (gastric, colon, oesophageal, lung, renal, breast, prostate, melanoma); moderate or severe liver dysfunction, defined as an alanine transaminase concentration $>120 \mathrm{IU} / 1$ (that is, more than three times the upper limit of normal) among patients without diagnosed chronic liver disease, as this is the severity at which guidelines recommend treatment is discontinued ${ }^{931}$; and moderate or serious myopathic events, ${ }^{9-1332}$ which for our study was defined as a diagnosis of myopathy or rhabdomyolysis or a raised creatine kinase concentration of four or more times the upper limit of normal, as this represents an event where treatment is likely to be discontinued. 
Table 2|Crude incidence per 10000 person years for study outcomes in both men and women

\begin{tabular}{|c|c|c|c|c|c|c|}
\hline \multirow[b]{2}{*}{ Outcomes } & \multicolumn{3}{|c|}{ Women } & \multicolumn{3}{|c|}{ Men } \\
\hline & $\begin{array}{l}\text { Incident } \\
\text { cases }\end{array}$ & $\begin{array}{l}\text { Person } \\
\text { years }\end{array}$ & $\begin{array}{c}\text { Rate per } 10000 \text { person } \\
\text { years }(95 \% \mathrm{Cl})\end{array}$ & $\begin{array}{l}\text { Incident } \\
\text { cases }\end{array}$ & $\begin{array}{l}\text { Person } \\
\text { years }\end{array}$ & $\begin{array}{c}\text { Rate per } 10000 \text { person } \\
\text { years }(95 \% \mathrm{Cl})\end{array}$ \\
\hline Cataract & 22010 & 4638731 & 47.45 (46.83 to 48.08$)$ & 14531 & 4434520 & 32.77 (32.24 to 33.31$)$ \\
\hline Osteoporotic fracture & 13475 & 4646441 & $29.0(28.52$ to 29.49$)$ & 4802 & 4444729 & $10.80(10.50$ to 11.11$)$ \\
\hline Breast cancer & 9823 & 4700328 & 20.90 (20.49 to 21.32$)$ & NA & NA & NA \\
\hline Prostate cancer & NA & NA & NA & 7129 & 4486286 & 15.89 (15.53 to 16.26$)$ \\
\hline $\begin{array}{l}\text { Moderate or serious liver } \\
\text { dysfunction }\end{array}$ & 7218 & 4752020 & 15.19 (14.84 to 15.54$)$ & 7802 & 4491763 & 17.37 (16.99 to 17.76$)$ \\
\hline Venous thromboembolism & 6628 & 4708712 & 14.08 (13.74 to 14.42$)$ & 5571 & 4475491 & $12.45(12.13$ to 12.78$)$ \\
\hline Dementia & 5505 & 4759939 & 11.57 (11.26 to 11.87$)$ & 3279 & 4512950 & 7.27 (7.02 to 7.52$)$ \\
\hline Rheumatoid arthritis & 3961 & 4717553 & $8.40(8.14$ to 8.66$)$ & 1769 & 4498971 & 3.93 (3.75 to 4.12$)$ \\
\hline Lung cancer & 2401 & 4776939 & $5.03(4.83$ to 5.23$)$ & 3600 & 4519197 & 7.97 (7.71 to 8.23$)$ \\
\hline Parkinson's disease & 1534 & 4768474 & 3.22 (3.06 to 3.38$)$ & 2019 & 4509935 & $4.48(4.29$ to 4.68$)$ \\
\hline Colon cancer & 1970 & 4769095 & $4.13(3.95$ to 4.32$)$ & 2182 & 4512911 & $4.84(4.64$ to 5.04$)$ \\
\hline Melanoma & 1174 & 4767753 & $2.46(2.33$ to 2.61$)$ & 896 & 4516849 & 1.98 (1.86 to 2.12$)$ \\
\hline Acute renal failure & 860 & 4777274 & 1.80 (1.68 to 1.92$)$ & 1109 & 4519879 & $2.45(2.31$ to 2.60$)$ \\
\hline Oesophageal cancer & 584 & 4778945 & $1.22(1.13$ to 1.33$)$ & 1225 & 4521683 & 2.71 (2.56 to 2.87$)$ \\
\hline $\begin{array}{l}\text { Moderate or serious } \\
\text { myopathy }\end{array}$ & 518 & 4777929 & 1.08 (0.99 to 1.18$)$ & 888 & 4520960 & 1.96 (1.84 to 2.10$)$ \\
\hline Gastric cancer & 380 & 4779154 & 0.80 (0.72 to 0.88$)$ & 713 & 4522171 & 1.58 (1.47 to 1.70$)$ \\
\hline Renal cancer & 959 & 4775022 & 2.01 (1.89 to 2.14$)$ & 2037 & 4512131 & $4.51(4.32$ to 4.71$)$ \\
\hline
\end{tabular}

\section{Predictor and exposure variables}

We identified new users of statins during the study period, with the remaining patients classified as non-users. To correspond to an intention to treat analysis we classified statin use by type of statin first prescribed (atorvastatin, simvastatin, fluvastatin, pravastatin, or rosuvastatin). We examined starting dose using categories similar to those published elsewhere ${ }^{33}{ }^{34}$ collapsing categories when data were insufficient to support analysis. We compiled a list of potential predictor variables, which included established risk factors for each outcome from the literature or existing risk prediction scores, using similar definitions when possible.

\section{Statistical modelling}

To estimate the hazard ratios for each outcome for type of statin first prescribed for men and women separately, we used Cox proportional hazards models to compare new users with non-users, adjusting for potential confounding variables. So that we considered first events only we excluded patients from the analysis of each outcome when they had a diagnosis of the outcome at or before the baseline date. We used multiple imputation to replace missing values for body mass index and smoking status and used these values in our main analyses. ${ }^{35-38}$ We carried out five imputations. When appropriate we used fractional polynomials to model non-linear risk relations with continuous variables. ${ }^{39}$ When we found significant associations for individual statins we examined the effects of dose. We tested for interactions between statin use and age and between smoking and deprivation and included significant interactions in the final models. We carried out two global tests; one to check that there was no overall effect of individual statins, and, if that test gave significant results a test for equality of effects of individual statins. When the hazard ratio was less than 0.80 or greater than 1.20 and was statistically significant at the 0.01 level we considered the effect of statins to be significant.

\section{Time varying analyses}

When associations for individual statins were significant, we used a time varying Cox regression analysis to examine the effects of duration of use and time since stopping any statin. We examined statins overall and by type. To determine the risk of each outcome within a year, 1-3 years, 3-5 years, and five or more years of taking statins we compared non-users with new users. We also determined change in risks after stopping statins, categorised as stopping treatment within a year, 1-3 years, and three or more years. The date of stopping statins was taken to be 90 days after the date of the last recorded prescription.

\section{Self controlled case series analysis}

In addition, we undertook post hoc self controlled case series analyses for the significant outcomes other than cancer. The case series methodology was originally developed to assess adverse events to vaccination ${ }^{40}$ but has a wider application. ${ }^{41-43}$ It can be used to determine the relative incidence of the outcome of interest for periods of drug use compared with periods of nonuse in people with the outcome of interest. Inference is within individuals and hence implicitly controls for covariates that do not change over the study period.

For each outcome we selected the patients within the study cohort with the outcome of interest during the study period and ascertained dates when they started and finished taking statins. To improve adjustment for 
age we included non-users along with new users during the study period. To estimate relative rate ratios we used conditional Poisson regression and adjusted for age in five year bands. We then determined the relative rate ratios for individual statins during the period of use and the washout period (1-182 days after stopping statins) compared with the baseline periods of non-usage during each person's observation time. We removed the time period in the 28 days before starting statins and the day on which the first prescription was issued. For these analyses we combined men and women. As the occurrence of an event may alter the probability of subsequent statin use we carried out an additional case series analysis restricted to new statin users and started the observation period at first use. ${ }^{44}$

\section{Number needed to treat or number needed to harm}

We calculated the number needed to treat (NNT) or number needed to harm (NNH) over five years for patients at high risk of cardiovascular disease based on a QRISK2 score of $20 \%$ or more, since this group is eligible for statin treatment. For each outcome we used Kaplan-Meier estimates to calculate the diseasefree probability at five years for non-users of statins in those aged 35-74 years. For these calculations we identified a cohort of patients who entered the study on the latest of their registration date and 1 January 2002 and who had not been prescribed statins, or had the outcome of interest by that date. These patients were censored at the earliest date of the diagnosis of interest, first statin prescription, death, deregistration with the practice, last upload of computerised data, or date at end of study. We calculated adjusted hazard ratios for each outcome for all types of statin treatment combined, adjusting for potential confounding variables. We then used these adjusted hazard ratios and the disease-free probability to calculate the NNT or NNH for each outcome according to a published formula. ${ }^{45}$ To enable comparisons and supplement data published elsewhere we also used these values to calculate the number of additional cases per 10000 patients treated over five years.

For cardiovascular disease, we used information from a recent meta-analysis of 10 primary prevention trials totalling over 70000 patients with risk factors for cardiovascular disease but without cardiovascular disease at baseline who were treated with statins or placebo and followed up for a median of 4.1 years. ${ }^{2}$ The meta-analysis reported that the effects of statins on major coronary events and cerebrovascular events were not significantly different according to age, sex, or diabetes status. ${ }^{2}$ We combined the published results for major coronary events and cerebrovascular events using a random effects model to calculate a summary relative risk for cardiovascular disease in statin users compared with non-users. We only included trials that reported both outcomes, assuming that individual patients did not have both outcomes. The overall odds ratio for cardiovascular events associated with statin use in this meta-analysis was 0.76 (95\% confidence interval 0.67 to 0.86 ), which is similar to that reported
Table $3 \mid$ Risk associated with statin type both in men and in women for non-significant and marginal outcomes

\begin{tabular}{llc} 
& \multicolumn{2}{l}{ Adjusted hazard ratio $(95 \% \mathrm{Cl})$} \\
\cline { 2 - 3 } Outcomes & Women
\end{tabular}

Rheumatoid arthritis:

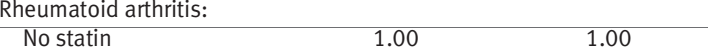

Simvastatin $\quad 0.96(0.84$ to 1.09$) \quad 1.12(0.96$ to 1.32$)$

$\begin{array}{lll}\text { Atorvastatin } & 0.97(0.81 \text { to } 1.17) & 1.06(0.84 \text { to } 1.34)\end{array}$

$\begin{array}{lll}\text { Fluvastatin } & 1.00(0.52 \text { to } 1.93) & 1.07(0.48 \text { to } 2.39)\end{array}$

$\begin{array}{lll}\text { Pravastatin } & 0.78(0.49 \text { to } 1.26) & 1.13(0.68 \text { to } 1.88)\end{array}$

\begin{tabular}{lll}
\hline Rosuvastatin & $0.84(0.44$ to 1.61$)$ & $0.72(0.27$ to 1.92$)$ \\
\hline
\end{tabular}

Parkinson's disease:

$\begin{array}{lcc}\text { No statin } & 1.00 & 1.00 \\ \text { Simvastatin } & 0.84(0.71 \text { to } 1.00) & 0.85(0.74 \text { to } 0.98)\end{array}$

Atorvastatin $\quad 0.79(0.61$ to 1.01$) \quad 0.89(0.73$ to 1.08$)$

\begin{tabular}{lll} 
Fluvastatin & $1.59(0.87$ to 2.89$)$ & $0.47(0.21$ to 1.06$)$ \\
\hline
\end{tabular}

$\begin{array}{lll}\text { Pravastatin } & 0.89(0.52 \text { to } 1.51) & 0.73(0.47 \text { to } 1.15) \\ \text { Rosuvastatin } & 1.05(0.50 \text { to } 2.20) & 0.73(0.35 \text { to } 1.54)\end{array}$

$\begin{array}{lll}\text { Rosuvastatin } & 1.05(0.50 \text { to } 2.20) & 0.73(0.35 \text { to } 1.54)\end{array}$

Venous thromboembolism:

No statin

$\begin{array}{lcc}\text { No statin } & 1.00 & 1.00 \\ \text { Simvastatin } & 0.91(0.83 \text { to } 0.99) & 0.88(0.80 \text { to } 0.97)\end{array}$

Atorvastatin $\quad 0.86(0.76$ to 0.99$) \quad 0.86(0.75$ to 0.97$)$

Fluvastatin $\quad 0.68(0.41$ to 1.13$) \quad 1.04(0.70$ to 1.54$)$

\begin{tabular}{lll} 
Fluvastatin & $0.68(0.41$ to 1.13$)$ & $1.04(0.70$ to 1.54$)$ \\
\hline Pravastatin & $1.05(0.80$ to 1.38$)$ & $1.00(0.76$ to 1.31$)$ \\
\hline
\end{tabular}

\begin{tabular}{lll} 
Rosuvastatin & $0.61(0.36$ to 1.03$)$ & $0.53(0.29$ to 0.95$)$ \\
\hline
\end{tabular}

Dementia:

\begin{tabular}{ccc} 
No statin & 1.00 & 1.00 \\
\hline
\end{tabular}

Simvastatin $\quad 0.88(0.81$ to 0.96$)-0.92(0.83$ to 1.02$)$

Atorvastatin $\quad 0.84(0.74$ to 0.96$) \quad 0.86(0.74$ to 1.00$)$

$\begin{array}{lll}\text { Fluvastatin } & 0.96(0.65 \text { to } 1.42) & 0.83(0.53 \text { to } 1.30)\end{array}$

Pravastatin $\quad 0.90(0.68$ to 1.18$) \quad 1.23(0.94$ to 1.60$)$

Rosuvastatin

Osteoporotic fracture:

No statin

$\begin{array}{rr}1.00 & 1.00\end{array}$

( $\quad 0.98(0.92$ to 1.05$) \quad 0.97(0.87$ to 1.08$)$

Atorvastatin $\quad 0.95(0.87$ to 1.04$) \quad 1.07(0.93$ to 1.24$)$

\begin{tabular}{lll} 
Fluvastatin & $0.78(0.57$ to 1.08$)$ & $0.74(0.44$ to 1.26$)$ \\
\hline
\end{tabular}

$\begin{array}{lll}\text { Pravastatin } & 0.91(0.75 \text { to } 1.11) & 1.00(0.73 \text { to } 1.36) \\ \text { Rosuvastatn } & 0.89(0.65 \text { to } 1.21) & 0.68(0.36 \text { to } 1.76)\end{array}$

Rosuvastatin $\quad 0.89(0.65$ to 1.21$) \quad 0.68(0.36$ to 1.26$)$

Gastric cancer:

No statin $\quad 1.00 \quad 1.00$

Simvastatin $\quad 0.79(0.55$ to 1.13$) \quad 0.83$ (0.65 to 1.04$)$

Atorvastatin $\quad 0.92(0.57$ to 1.49$) \quad 0.75(0.53$ to 1.06$)$

\begin{tabular}{lll} 
Fluvastatin & $1.31(0.32$ to 5.28$)$ & $0.90(0.33$ to 2.41$)$ \\
\hline
\end{tabular}

Pravastatin $\quad 0.85(0.27$ to 2.66$) \quad 0.65(0.29$ to 1.46$)$

Rosuvastatin

Colon cancer:

$\begin{array}{lll}\text { No statin } & 1.00 & 1.00\end{array}$

Simvastatin $\quad 0.89(0.76$ to 1.05$) \quad 1.02(0.90$ to 1.17$)$

Atorvastatin $\quad 0.85(0.68$ to 1.06$) \quad 0.90(0.74$ to 1.09$)$

Fluvastatin $\quad 0.25(0.06$ to 1.00$) \quad 1.14(0.66$ to 1.97$)$

$\begin{array}{lll}\text { Pravastatin } & 0.79(0.46 \text { to } 1.34) & 0.49(0.28 \text { to } 0.86) \\ \text { Rosuvastain } & 1.03(0.51 \text { to } 2.08) & 2.04(1.29 \text { to }\end{array}$

Rosuvastatin $\quad 1.03(0.51$ to 2.08$) \quad 2.04(1.29$ to 3.21$)$

Renalcancer:

$\begin{array}{lll}\text { Renal cancer: } & & \\ \text { No statin } & 1.00 & 1.00\end{array}$

\begin{tabular}{lcc} 
No statin & 1.00 & 1.00 \\
\hline Simvastatin & $1.07(0.86$ to 1.32$)$ & $1.10(0.97$ to 1.26$)$ \\
\hline
\end{tabular}

Atorvastatin $\quad 1.15(0.86$ to 1.54$) \quad 1.10(0.91$ to 1.32$)$

Fluvastatin $\quad 1.15(0.43$ to 3.07$) \quad 0.54(0.24$ to 1.21$)$

$\begin{array}{lll}\text { Pravastatin } & 0.99(0.49 \text { to } 1.99) & 1.02(0.68 \text { to } 1.53)\end{array}$

$\begin{array}{lll}\text { Rosuvastatin } & 1.39(0.58 \text { to } 3.37) & 0.78(0.37 \text { to } 1.65)\end{array}$

No statin

Simvastatin

$1.10(0.96$ to 1.25$) \quad 1.11(1.01$ to 1.23$)$

Atorvastatin $\quad 0.88(0.72$ to 1.09$) \quad 0.95(0.82$ to 1.10$)$

Fluvastatin

Pravastatin

\begin{tabular}{lll} 
Rosuvastatin & $1.28(0.71$ to 2.32$)$ & $0.83(0.47$ to 1.46$)$ \\
\hline
\end{tabular}

Melanoma:

No statin

\begin{tabular}{lcc} 
Simvastatin & 1.00 & 1.00 \\
\hline (0.79 to 1.32$)$ & $1.11(0.88$ to 1.40$)$
\end{tabular}

Atorvastatin $\quad 0.94(0.64$ to 1.37$) \quad 1.20(0.87$ to 1.66$)$

Fluvastatin Insufficient data 1.59 (0.66 to 3.85$)$

Fluvastatin

Rosuvastatin

Breast cancer:

No statin

Simvastatin

Atorvastatin

Fluvastatin

Pravastatin

Rosuvastatin

Prostate cancer:

No statin

Simvastatin

Atorvastatin

Fluvastatin

Pravastatin

Rosuvastatin

$\begin{array}{cc}\text { Insufficient data } & 1.59(0.66 \text { to } 3.85) \\ 0.18(0.02 \text { to } 1.27) & 1.74(0.98 \text { to } 3.10)\end{array}$

$0.79(0.20$ to 3.18$) \quad 1.12$ (0.36 to 3.49$)$

n

1.00

1.09 (1.00 to 1.18$)$

$1.01(0.90$ to 1.14$)$

$0.74(0.45$ to 1.21$)$

$0.93(0.70$ to 1.23$)$

$0.75(0.47$ to 1.19$)$

1.00

NA

NA

NA

NA

$\mathrm{NA}=$ not applicable. 
Table $4 \mid$ Risk of significant outcomes associated with statin type both in men and in women

\begin{tabular}{|c|c|c|}
\hline \multirow[b]{2}{*}{ Outcomes } & \multicolumn{2}{|c|}{ Adjusted hazard ratio $(95 \% \mathrm{Cl})$} \\
\hline & Women & Men \\
\hline \multicolumn{3}{|c|}{$\begin{array}{l}\text { Moderate or serious } \\
\text { myopathy: }\end{array}$} \\
\hline No statin & 1.00 & 1.00 \\
\hline Simvastatin & $3.03(2.35$ to 3.91$)$ & $6.14(5.09$ to 7.40$)$ \\
\hline Atorvastatin & $2.90(2.09$ to 4.01$)$ & $6.68(5.32$ to 8.39$)$ \\
\hline Fluvastatin & Insufficient data & $4.79(2.12$ to 10.80$)$ \\
\hline Pravastatin & 2.64 (1.29 to 5.39$)$ & $4.84(2.86$ to 8.17$)$ \\
\hline Rosuvastatin & $5.41(2.64$ to 11.07$)$ & 4.21 (1.87 to 9.48$)$ \\
\hline \multicolumn{3}{|c|}{ Acute renal failure: } \\
\hline No statin & 1.00 & 1.00 \\
\hline Simvastatin & 1.50 (1.23 to 1.83$)$ & 1.61 (1.37 to 1.90$)$ \\
\hline Atorvastatin & 1.57 (1.22 to 2.03$)$ & 1.63 (1.31 to 2.02$)$ \\
\hline Fluvastatin & 2.19 (1.13 to 4.27$)$ & $1.16(0.55$ to 2.44$)$ \\
\hline Pravastatin & $2.07(1.28$ to 3.34$)$ & 1.71 (1.12 to 2.61$)$ \\
\hline Rosuvastatin & 1.03 (0.39 to 2.78$)$ & $1.74(0.86$ to 3.50$)$ \\
\hline \multicolumn{3}{|l|}{ Cataract: } \\
\hline No statin & 1.00 & 1.00 \\
\hline Simvastatin & $1.30(1.25$ to 1.36$)$ & $1.31(1.25$ to 1.38$)$ \\
\hline Atorvastatin & 1.30 (1.22 to 1.37$)$ & $1.32(1.24$ to 1.41$)$ \\
\hline Fluvastatin & $1.26(1.05$ to 1.52$)$ & $1.16(0.95$ to 1.42$)$ \\
\hline Pravastatin & 1.40 (1.24 to 1.57$)$ & 1.31 (1.15 to 1.50$)$ \\
\hline Rosuvastatin & 1.25 (1.04 to 1.51$)$ & $1.56(1.28$ to 1.90$)$ \\
\hline \multicolumn{3}{|c|}{$\begin{array}{l}\text { Moderate or serious } \\
\text { liver dysfunction: }\end{array}$} \\
\hline No statin & 1.00 & 1.00 \\
\hline Simvastatin & 1.52 (1.38 to 1.66$)$ & 1.54 (1.41 to 1.68$)$ \\
\hline Atorvastatin & 1.53 (1.35 to 1.73$)$ & $1.56(1.39$ to 1.74$)$ \\
\hline Fluvastatin & 2.53 (1.84 to 3.47$)$ & 1.97 (1.43 to 2.72$)$ \\
\hline Pravastatin & 1.50 (1.15 to 1.97$)$ & 1.21 (0.93 to 1.58$)$ \\
\hline Rosuvastatin & 1.31 (0.87 to 1.98$)$ & 1.46 (1.01 to 2.11$)$ \\
\hline \multicolumn{3}{|c|}{ Oesophageal cancer: } \\
\hline No statin & 1.00 & 1.00 \\
\hline Simvastatin & $0.69(0.50$ to 0.94$)$ & 0.82 (0.68 to 0.99$)$ \\
\hline Atorvastatin & 0.73 (0.47 to 1.13$)$ & $0.73(0.55$ to 0.96$)$ \\
\hline Fluvastatin & Insufficient data & $0.60(0.22$ to 1.60$)$ \\
\hline Pravastatin & 0.72 (0.27 to 1.92$)$ & $0.56(0.28$ to 1.13$)$ \\
\hline Rosuvastatin & 0.41 (0.06 to 2.93$)$ & 0.91 (0.38 to 2.20$)$ \\
\hline
\end{tabular}

See web extra for variables that were adjusted for in hazard ratios.

elsewhere. ${ }^{3}$ We then combined this value with the cardiovascular disease-free probability at five years to calculate the NNT for cardiovascular disease and the number of cases of cardiovascular disease prevented per 10000 patients treated.

\section{RESULTS}

Overall, 557 general practices in England and Wales supplying data to the QResearch database met the inclusion criteria, of which 368 were randomly assigned to the study dataset. In total, 2121786 patients were aged 30-84 at study entry, of whom $1778770(83.8 \%)$ had not been prescribed statins, $9513(0.5 \%)$ were past users, 107581 (5.1\%) were current users, and $225922(10.7 \%)$ were new users during the study period. Of the new users, 159790 (70.7\%) had been prescribed simvastatin, $50328(22.3 \%)$ atorvastatin, $8103(3.6 \%)$ pravastatin, $4497(1.9 \%)$ rosuvastatin, and $3204(1.4 \%)$ fluvastatin.

Compared with non-users of statins, new users tended to be older and were more likely to be men and to have comorbidities such as atrial fibrillation, cardiovascular disease, peripheral vascular disease, treated hypertension, diabetes, and chronic kidney disease (table 1). They were also more likely to have results recorded on computer for liver function tests and creatine kinase concentrations.

Table 2 shows the crude incidence of each outcome in men and women separately per 10000 person years. Overall, there were 1969 incident cases of acute renal failure, 12199 of venous thromboembolism, 5730 of rheumatoid arthritis, 36541 of cataract, 3553 of Parkinson's disease, 8784 of dementia, 18277 of osteoporotic fracture, 1093 of gastric cancer, 1809 of oesophageal cancer, 4152 of colon cancer, 6001 of lung cancer, 2070 of melanoma, 2996 of renal cancer, 9823 of breast cancer, 7129 of prostate cancer, 15020 of moderate or serious liver dysfunction, and 1406 of moderate or serious myopathy. Sixty two patients had both acute renal failure and moderate or serious myopathy.

\section{Non-significant and marginal clinical outcomes}

The associations between statins and Parkinson's disease, rheumatoid arthritis, venous thromboembolism, dementia, osteoporotic fracture, gastric cancer, lung cancer, melanoma, renal cancer, breast cancer, and prostate cancer were not clinically significant and the overall tests for statins were not statistically significant (at $\mathrm{P}<0.01$ ) (table 3).

Although the association between any statin and colon cancer was not significant in women, a significant effect was present in men (overall $\mathrm{P}=0.002$ ). The risk of colon cancer was lowest among men prescribed pravastatin (adjusted hazard ratio 0.47, 95\% confidence interval 0.28 to 0.86 ), although there was no evidence of a dose-response relation, and increased among men prescribed rosuvastatin (2.07, 1.29 to 3.21). Time varying analysis showed that the risk was increased after three years of treatment $(3.27,1.69$ to 6.32 ) but returned to normal within a year of stopping treatment.

\section{Significant clinical outcomes}

Outcomes significantly associated with statin use were myopathy, cataract, acute renal failure, oesophageal cancer, and moderate or serious liver dysfunction (table 4).

\section{Moderate or serious liver dysfunction}

Overall, statins were associated with an increased risk of liver dysfunction in both men and women (table 4). In women there was some indication of differences between the effects of individual statins (overall test $\mathrm{P}=0.058)$. The highest risk was associated with fluvastatin $(2.53,1.84$ to 3.47$)$, which was significantly higher than that with simvastatin $(1.52,1.38$ to 1.66$)$. In men, differences between the effects of individual statins were significant (overall test $\mathrm{P}=0.0045$ ). The highest risk was associated with fluvastatin (1.97 1.43 to 2.72 ) and the lowest with pravastatin (1.21, 0.93 to 1.58$)$.

A dose-response effect was evident in women, with an increased risk associated with higher doses 
Table 5 |Risk of significant outcomes associated with type and dose of statin both in men and in women

\begin{tabular}{|c|c|c|c|c|}
\hline \multirow[b]{2}{*}{ Outcomes } & \multicolumn{2}{|c|}{ Women } & \multicolumn{2}{|c|}{ Men } \\
\hline & Cases/total & $\begin{array}{c}\text { Adjusted hazard ratio } \\
\qquad(95 \% \mathrm{Cl})\end{array}$ & Cases/total & $\begin{array}{c}\text { Adjusted hazard ratio } \\
\qquad(95 \% \mathrm{Cl})\end{array}$ \\
\hline \multicolumn{5}{|l|}{ Moderate or serious myopathy: } \\
\hline No statin & $325 / 908822$ & 1.00 & 483/868 819 & 1.00 \\
\hline Simvastatin $10 / 20 \mathrm{mg} /$ day & $81 / 46056$ & 2.91 (2.19 to 3.88 ) & $162 / 48892$ & $6.12(4.97$ to 7.55$)$ \\
\hline Simvastatin $40 / 80 \mathrm{mg} /$ day & $43 / 27775$ & 3.30 (2.32 to 4.69$)$ & $97 / 36978$ & 6.11 (4.79 to 7.80$)$ \\
\hline Atorvastatin $10 \mathrm{mg} /$ day & $42 / 17065$ & 2.98 (2.09 to 4.26$)$ & $80 / 18601$ & 6.11 (4.70 to 7.93$)$ \\
\hline Atorvastatin $20 / 40 / 80 \mathrm{mg} /$ day & $11 / 6488$ & 2.62 (1.42 to 4.84$)$ & $39 / 8138$ & 8.18 (5.82 to 11.50$)$ \\
\hline Fluvastatin $20 \mathrm{mg} /$ day & $0 / 575$ & Insufficient data & $5 / 592$ & 11.86 (4.88 to 28.85 ) \\
\hline Fluvastatin $40 / 80 \mathrm{mg} /$ day & 0/906 & Insufficient data & $1 / 1126$ & $1.20(0.17$ to 8.53$)$ \\
\hline Pravastatin $10 / 20$ mg/day & 4/1779 & $2.60(0.96$ to 7.04$)$ & $5 / 1932$ & 3.62 (1.49 to 8.78$)$ \\
\hline Pravastatin $40 \mathrm{mg} /$ day & 4/1913 & 2.68 (0.99 to 7.25$)$ & $10 / 2476$ & 5.79 (3.07 to 10.91$)$ \\
\hline Rosuvastatin all & $8 / 2151$ & 5.41 (2.64 to 11.07$)$ & $6 / 2345$ & 4.19 (1.86 to 9.45$)$ \\
\hline \multicolumn{5}{|l|}{ Acute renal failure: } \\
\hline No statin & $579 / 908720$ & 1.00 & $711 / 868548$ & 1.00 \\
\hline Simvastatin $10 / 20 \mathrm{mg} /$ day & $106 / 46009$ & 1.38 (1.10 to 1.74$)$ & $142 / 48824$ & 1.39 (1.14 to 1.70$)$ \\
\hline Simvastatin $40 / 80 \mathrm{mg} /$ day & $63 / 27746$ & 1.75 (1.32 to 2.32$)$ & 109/36 921 & 2.02 (1.63 to 2.52$)$ \\
\hline Atorvastatin $10 \mathrm{mg} /$ day & $57 / 17048$ & $1.43(1.07$ to 1.92$)$ & $85 / 18556$ & 1.63 (1.28 to 2.07$)$ \\
\hline Atorvastatin $20 / 40 / 80 \mathrm{mg} /$ day & $24 / 6479$ & 2.03 (1.34 to 3.09) & $24 / 8130$ & 1.62 (1.07 to 2.44$)$ \\
\hline Fluvastatin $20 \mathrm{mg} /$ day & $7 / 577$ & 4.35 (2.05 to 9.23$)$ & $1 / 591$ & $0.48(0.07$ to 3.42$)$ \\
\hline Fluvastatin $40 / 80 \mathrm{mg} /$ day & $2 / 905$ & 0.80 (0.20 to 3.21$)$ & $6 / 1121$ & $1.50(0.67$ to 3.37$)$ \\
\hline Pravastatin $10 / 20 \mathrm{mg} /$ day & $8 / 1777$ & 1.94 (0.96 to 3.92$)$ & $6 / 1929$ & $0.98(0.44$ to 2.20$)$ \\
\hline Pravastatin $40 \mathrm{mg} /$ day & 10/1907 & 2.18 (1.16 to 4.09$)$ & $17 / 2476$ & 2.31 (1.42 to 3.75$)$ \\
\hline Rosuvastatin all & $4 / 2150$ & 1.03 (0.38 to 2.78$)$ & $8 / 2344$ & 1.73 (0.86 to 3.50$)$ \\
\hline \multicolumn{5}{|l|}{ Cataract: } \\
\hline No statin & $16543 / 896717$ & 1.00 & 10 068/861 216 & 1.00 \\
\hline Simvastatin $10 / 20 \mathrm{mg} /$ day & $2350 / 42755$ & $1.30(1.24$ to 1.36$)$ & $1848 / 46566$ & $1.32(1.24$ to 1.39$)$ \\
\hline Simvastatin $40 / 80 \mathrm{mg} /$ day & $1090 / 25877$ & 1.31 (1.23 to 1.40$)$ & $973 / 35346$ & $1.30(1.21$ to 1.40$)$ \\
\hline Atorvastatin $10 \mathrm{mg} /$ day & $1180 / 15861$ & 1.31 (1.23 to 1.40$)$ & $921 / 17753$ & $1.29(1.20$ to 1.39$)$ \\
\hline Atorvastatin $20 / 40 / 80 \mathrm{mg} /$ day & $334 / 6113$ & 1.24 (1.11 to 1.39$)$ & $293 / 7882$ & $1.44(1.28$ to 1.63$)$ \\
\hline Fluvastatin $20 \mathrm{mg} /$ day & $47 / 553$ & $1.27(0.95$ to 1.69$)$ & $37 / 566$ & 1.37 (0.99 to 1.89$)$ \\
\hline Fluvastatin $40 / 80 \mathrm{mg} /$ day & $71 / 833$ & $1.26(1.00$ to 1.60$)$ & $61 / 1070$ & $1.06(0.83$ to 1.37$)$ \\
\hline Pravastatin $10 / 20 \mathrm{mg} /$ day & $124 / 1662$ & 1.24 (1.04 to 1.48$)$ & $108 / 1846$ & 1.39 (1.15 to 1.68$)$ \\
\hline Pravastatin $40 \mathrm{mg} /$ day & $158 / 1778$ & 1.55 (1.32 to 1.82$)$ & $124 / 2357$ & $1.25(1.05$ to 1.50$)$ \\
\hline Rosuvastatin all & $113 / 2029$ & 1.25 (1.04 to 1.51$)$ & $98 / 2238$ & $1.56(1.28$ to 1.90$)$ \\
\hline \multicolumn{5}{|l|}{ Moderate or serious liver dysfunction: } \\
\hline No statin & $6055 / 907313$ & 1.00 & $6359 / 866763$ & 1.00 \\
\hline Simvastatin $10 / 20 \mathrm{mg} /$ day & $470 / 45573$ & $1.47(1.32$ to 1.63$)$ & $521 / 48271$ & $1.39(1.25$ to 1.54$)$ \\
\hline Simvastatin $40 / 80 \mathrm{mg} /$ day & $247 / 27476$ & $1.62(1.41$ to 1.86$)$ & $393 / 36464$ & 1.79 (1.60 to 2.01$)$ \\
\hline Atorvastatin $10 \mathrm{mg} /$ day & $221 / 16948$ & 1.37 (1.19 to 1.58$)$ & $277 / 18412$ & $1.45(1.27$ to 1.65$)$ \\
\hline Atorvastatin $20 / 40 / 80 \mathrm{mg} /$ day & $106 / 6440$ & 2.00 (1.64 to 2.44$)$ & $127 / 8049$ & $1.86(1.55$ to 2.24$)$ \\
\hline Fluvastatin 20 mg/day & $10 / 574$ & $1.64(0.88$ to 3.06$)$ & $8 / 592$ & $1.20(0.60$ to 2.40$)$ \\
\hline Fluvastatin $40 / 80 \mathrm{mg} /$ day & $30 / 897$ & 3.08 (2.14 to 4.43$)$ & $31 / 1120$ & 2.37 (1.66 to 3.38 ) \\
\hline Pravastatin $10 / 20 \mathrm{mg} /$ day & 19/1765 & $1.06(0.68$ to 1.67$)$ & $27 / 1904$ & $1.31(0.90$ to 1.92$)$ \\
\hline Pravastatin 40 mg/day & $37 / 1897$ & 1.91 (1.37 to 2.65$)$ & $30 / 2453$ & 1.13 (0.78 to 1.62$)$ \\
\hline Rosuvastatin all & $23 / 2132$ & $1.31(0.87$ to 1.97$)$ & 29/2316 & $1.46(1.01$ to 2.11$)$ \\
\hline \multicolumn{5}{|l|}{ Oesophageal cancer: } \\
\hline No statin & $506 / 908816$ & 1.00 & $1009 / 868647$ & 1.00 \\
\hline Simvastatin $10 / 20 \mathrm{mg} /$ day & $31 / 46067$ & 0.62 (0.43 to 0.91$)$ & $104 / 48893$ & 0.91 (0.73 to 1.12 ) \\
\hline Simvastatin $40 / 80 \mathrm{mg} /$ day & $19 / 27788$ & $0.82(0.51$ to 1.31$)$ & $42 / 36968$ & $0.66(0.48$ to 0.91$)$ \\
\hline Atorvastatin $10 \mathrm{mg} /$ day & $16 / 17078$ & 0.67 (0.40 to 1.11$)$ & $38 / 18608$ & 0.68 (0.49 to 0.95$)$ \\
\hline Atorvastatin $20 / 40 / 80 \mathrm{mg} /$ day & $7 / 6489$ & 0.94 (0.44 to 2.00$)$ & $15 / 8138$ & $0.86(0.51$ to 1.44$)$ \\
\hline Fluvastatin $20 \mathrm{mg} /$ day & $0 / 577$ & Insufficient data & $1 / 593$ & 0.46 (0.06 to 3.26$)$ \\
\hline Fluvastatin $40 / 80 \mathrm{mg} /$ day & $0 / 905$ & Insufficient data & $3 / 1127$ & $0.66(0.21$ to 2.07$)$ \\
\hline Pravastatin $10 / 20 \mathrm{mg} /$ day & $0 / 1779$ & Insufficient data & $3 / 1933$ & 0.48 (0.16 to 1.50$)$ \\
\hline Pravastatin $40 \mathrm{mg} /$ day & 4/1913 & 1.37 (0.51 to 3.67$)$ & $5 / 2477$ & 0.62 (0.26 to 1.50$)$ \\
\hline Rosuvastatin all & $1 / 2152$ & 0.41 (0.06 to 2.92$)$ & $5 / 2345$ & $0.91(0.38$ to 2.20$)$ \\
\hline
\end{tabular}

Hazard ratios are adjusted for same variables as table 4 (see web extra). 
compared with lower doses (table 5). For example, the adjusted hazard ratio for fluvastatin was 3.08 (2.14 to $4.43)$ at high dose $(\geq 20 \mathrm{mg})$ compared with $1.64(0.88$ to 3.06$)$ at low dose $(\leq 20 \mathrm{mg})$. The corresponding values for men were 2.37 (1.66 to 3.38) and 1.20 (0.60 to 2.40$)$. This pattern was similar with the other statins.

The risk of liver dysfunction was highest within the first year of treatment with any statin: the adjusted hazard ratio for women was 2.38 (2.11 to 2.70) and for men was 2.32 (2.07 to 2.59). The hazard ratio in the 1-3 years after starting treatment for women was 1.39 (1.23 to 1.57) and for men was 1.35 (1.21 to 1.51). After stopping statins the risks returned to normal between one and three years in women and from three years in men. Further details on the analyses of duration are available from the authors.

\section{Moderate or serious myopathy}

All statins were associated with an increased risk of myopathy (table 4) apart from fluvastatin in women, where numbers were too small for analysis. The direct comparison test showed no significant difference between the effects of individual statins either in men $(\mathrm{P}=0.57)$ or in women $(\mathrm{P}=0.61)$.

The adjusted hazard ratios in table 5 show some evidence of a dose-response in men prescribed atorvastatin and pravastatin: 6.11 (4.79 to 7.80) for low dose (10 mg/day) atorvastatin compared with 8.18 (5.82 to 11.50) for high dose ( $\geq 20 \mathrm{mg} /$ day) atorvastatin, and 3.62 (1.49 to 8.78$)$ for low dose $(\leq 20 \mathrm{mg} /$ day $)$ pravastatin compared with 5.79 (3.07 to 10.91) for high dose
(40 mg/day) pravastatin. The confidence intervals were, however, wide owing to small numbers in each dose category.

The time varying analysis showed that the risk was highest within the first year of starting treatment: the adjusted hazard ratio in women was 4.30 (2.98 to 6.21) and in men was 9.96 (7.66 to 12.96). The increase persisted during treatment as well as on stopping treatment. From three years after stopping statins, the adjusted hazard ratio in women was 4.65 (2.32 to 9.28 ) and in men was 5.86 (2.84 to 12.06 ).

\section{Cataract}

Each statin was associated with an increased risk of cataract in both men and women, apart from fluvastatin in men, owing to small numbers. The direct comparison test showed no significant difference between the effects of individual statins in men $(\mathrm{P}=0.32)$ or in women $(\mathrm{P}=0.82)$.

There was no evidence of a dose-response relation (table 5). The time varying analysis showed the risk was significantly increased within a year of starting statins, persisted during treatment, and returned to normal within the first year after stopping treatment.

\section{Oesophageal cancer}

The risk of oesophageal cancer decreased in both men and women prescribed simvastatin $(0.69,0.50$ to 0.94 and $0.82,0.68$ to 0.99 , respectively). The risk was also significantly decreased in men prescribed atorvastatin $(0.73,0.55$ to 0.96$)$. The hazard ratios for the other

Table $6 \mid$ Relative incidence rate ratios from case series analysis for men and women combined for significant outcomes associated with statin type

\begin{tabular}{|c|c|c|c|c|}
\hline \multirow[b]{2}{*}{ Outcomes } & \multicolumn{4}{|c|}{ Incidence rate ratio $(95 \% \mathrm{Cl})$} \\
\hline & $\begin{array}{l}\text { Acute renal } \\
\text { failure }\end{array}$ & Cataract & $\begin{array}{l}\text { Moderate or serious } \\
\text { liver dysfunction }\end{array}$ & $\begin{array}{l}\text { Moderate or serious } \\
\text { myopathy }\end{array}$ \\
\hline \multicolumn{5}{|l|}{ Simvastatin: } \\
\hline Period of non-use & 1.00 & 1.00 & 1.00 & 1.00 \\
\hline Period of use & 1.57 (1.27 to 1.95$)$ & $1.18(1.13$ to 1.24$)$ & $1.49(1.36$ to 1.63$)$ & 20.66 (14.68 to 29.06$)$ \\
\hline Washout period* & 2.21 (1.40 to 3.5$)$ & $0.94(0.8$ to 1.11$)$ & $1.10(0.86$ to 1.41$)$ & 3.81 (2.04 to 7.11$)$ \\
\hline \multicolumn{5}{|l|}{ Atorvastatin: } \\
\hline Period of non-use & 1.00 & 1.00 & 1.00 & 1.00 \\
\hline Period of use & 1.17 (0.83 to 1.67$)$ & $1.18(1.09$ to 1.29$)$ & $1.62(1.38$ to 1.91$)$ & $8.48(5.14$ to 13.99$)$ \\
\hline Washout period* & $1.60(0.74$ to 3.49$)$ & 0.77 (0.56 to 1.06$)$ & $0.90(0.58$ to 1.41$)$ & 2.84 (1.22 to 6.59$)$ \\
\hline \multicolumn{5}{|l|}{ Fluvastatin: } \\
\hline Period of non-use & 1.00 & 1.00 & 1.00 & 1.00 \\
\hline Period of use & Insufficient data & $1.50(1.04$ to 2.15$)$ & 2.38 (1.24 to 4.57$)$ & $9.20(0.84$ to 100.97$)$ \\
\hline Washout period* & Insufficient data & 1.06 (0.37 to 2.99$)$ & $0.73(0.10$ to 5.55$)$ & Insufficient data \\
\hline \multicolumn{5}{|l|}{ Pravastatin: } \\
\hline Period of non-use & 1.00 & 1.00 & 1.00 & 1.00 \\
\hline Period of use & $1.72(0.69$ to 4.25$)$ & $1.13(0.92$ to 1.4$)$ & 1.47 (0.95 to 2.26$)$ & 28.71 (5.51 to 149.56$)$ \\
\hline Washout period* & $2.68(0.53$ to 13.51$)$ & $1.23(0.67$ to 2.24$)$ & 0.81 (0.25 to 2.69$)$ & Insufficient data \\
\hline \multicolumn{5}{|l|}{ Rosuvastatin: } \\
\hline Period of non-use & 1.00 & 1.00 & 1.00 & 1.00 \\
\hline Period of use & 5.11 (1.05 to 24.92$)$ & 1.33 (1.01 to 1.75$)$ & 1.95 (1.11 to 3.41$)$ & $4.77(1.27$ to 17.88$)$ \\
\hline Washout period* & $5.66(0.55$ to 58.49$)$ & $1.26(0.54$ to 2.93$)$ & $0.62(0.08$ to 4.64$)$ & Insufficient data \\
\hline
\end{tabular}


Table $7 \mid$ Numbers needed to harm (NNH) or numbers needed to treat (NNT) and numbers of extra or prevented cases for each outcome over five years in patients aged 35-74 free of cardiovascular disease at baseline with QRISK2 score of $\geq 20 \%$ or $\geq 15 \%$

\begin{tabular}{|c|c|c|c|c|c|c|c|}
\hline \multirow[b]{2}{*}{ Variables } & \multirow[b]{2}{*}{$\begin{array}{l}\text { Adjusted hazard } \\
\text { ratio† for statin } \\
\text { use }(95 \% \mathrm{Cl})\end{array}$} & \multicolumn{3}{|c|}{ High risk patients (QRISK2 score $\geq 20 \%$ ) } & \multicolumn{3}{|c|}{ Medium risk patients (QRISK2 score $\geq 15 \%$ ) } \\
\hline & & $\begin{array}{l}5 \text { year risk of } \\
\text { outcome in } \\
\text { patients } \\
\text { unexposed to } \\
\text { statins }\end{array}$ & $\begin{array}{c}\text { NNH or NNT } \\
(95 \% \mathrm{Cl})\end{array}$ & $\begin{array}{l}\text { Estimated No of } \\
\text { extra (or } \\
\text { prevented) cases } \\
\text { per } 10000 \text { patients } \\
\text { treated }(95 \% \mathrm{Cl})\end{array}$ & $\begin{array}{l}5 \text { year risk of } \\
\text { outcome in } \\
\text { patients } \\
\text { unexposed to } \\
\text { statins }\end{array}$ & $\begin{array}{c}\text { NNH or NNT } \\
(95 \% \mathrm{Cl})\end{array}$ & $\begin{array}{l}\text { Estimated No of extra } \\
\text { (or prevented) cases } \\
\text { per } 10000 \text { patients } \\
\text { treated }(95 \% \mathrm{Cl})\end{array}$ \\
\hline \multicolumn{8}{|l|}{ Women } \\
\hline \multicolumn{8}{|l|}{ Potential benefits: } \\
\hline $\begin{array}{l}\text { Cardiovascular } \\
\text { disease* }\end{array}$ & $0.76(0.67$ to 0.86$)$ & 0.1184 & $-37(-64$ to -27$)$ & $-271(-374$ to -157$)$ & 0.0989 & $-44(-76$ to -32$)$ & $-228(-315$ to -132$)$ \\
\hline $\begin{array}{l}\text { Oesophageal } \\
\text { cancer }\end{array}$ & $0.68(0.52$ to 0.88$)$ & 0.0025 & $-1266(-3460$ to -850$)$ & $-8(-12$ to -3$)$ & 0.0021 & $-1483(-4053$ to -996$)$ & $-7(-10$ to -3$)$ \\
\hline \multicolumn{8}{|l|}{ Potential harms: } \\
\hline Acute renal failure & $1.56(1.31$ to 1.86$)$ & 0.0041 & 434 (284 to 783$)$ & 23 (13 to 35$)$ & 0.0030 & $593(388$ to 1070$)$ & 17 (9 to 26$)$ \\
\hline Cataract & $1.3(1.26$ to 1.35$)$ & 0.1089 & 33 (28 to 38$)$ & 307 (260 to 355$)$ & 0.0882 & $40(34$ to 47$)$ & 252 (213 to 292$)$ \\
\hline Liver dysfunction & $1.53(1.41$ to 1.66$)$ & 0.0140 & $136(109$ to 175$)$ & $74(57$ to 91$)$ & 0.0123 & 154 (125 to 199$)$ & $65(50$ to 80$)$ \\
\hline Myopathy & $2.97(2.36$ to 3.74$)$ & 0.0020 & 259 (186 to 375$)$ & 39 (27 to 54$)$ & 0.0016 & $313(225$ to 453$)$ & $32(22$ to 44$)$ \\
\hline \multicolumn{8}{|l|}{ Men } \\
\hline \multicolumn{8}{|l|}{ Potential benefits: } \\
\hline $\begin{array}{l}\text { Cardiovascular } \\
\text { disease* }^{*}\end{array}$ & $0.76(0.67$ to 0.86$)$ & 0.1326 & $-33(-57$ to -24$)$ & $-301(-417$ to -174$)$ & 0.1156 & $-38(-65$ to -27$)$ & $-265(-366$ to -153$)$ \\
\hline $\begin{array}{l}\text { Oesophageal } \\
\text { cancer }\end{array}$ & $0.78(0.66$ to 0.91$)$ & 0.0042 & $-1082(-2807$ to -711$)$ & $-9(-14$ to -4$)$ & 0.0037 & $-1236(-3207$ to -812$)$ & $-8(-12$ to -3$)$ \\
\hline \multicolumn{8}{|l|}{ Potential harms: } \\
\hline Acute renal failure & 1.61 (1.39 to 1.87$)$ & 0.0047 & $346(245$ to 539$)$ & $29(19$ to 41$)$ & 0.0037 & 447 (316 to 696) & $22(14$ to 32$)$ \\
\hline Cataract & $1.32(1.26$ to 1.37$)$ & 0.0630 & $52(44$ to 63$)$ & 191 (158 to 225) & 0.0495 & $66(56$ to 80$)$ & 151 (125 to 178$)$ \\
\hline Liver dysfunction & $1.53(1.42$ to 1.66$)$ & 0.0133 & 142 (115 to 180$)$ & 71 (56 to 87$)$ & 0.0122 & 155 (126 to 197$)$ & 64 (51 to 79$)$ \\
\hline Myopathy & $6.15(5.19$ to 7.3$)$ & 0.0021 & 91 (74 to 112 ) & 110 (90 to 134$)$ & 0.0018 & 106 (87 to 130$)$ & 95 (77 to 116$)$ \\
\hline
\end{tabular}

Negative numbers indicate numbers needed to treat or cases prevented. Positive numbers indicate numbers needed to harm or extra cases.

*Odds ratios based on meta-analysis by Brugts et al. ${ }^{2}$

†Adjusted hazard ratios for all statins combined adjusted for same variables as in tables 4 and 5 (see web extra).

statins were of similar magnitude and all less than 1 , but they did not reach statistical significance possibly because of small numbers. The direct comparison test showed no significant difference between the effects of individual statins in either men $(\mathrm{P}=0.76)$ or women $(\mathrm{P}=0.99)$.

There was some evidence of a dose-response associated with simvastatin in men only: adjusted hazard ratio 0.91 ( 0.73 to 1.12$)$ for low dose simvastatin (10/ $20 \mathrm{mg}$ ) and 0.66 (0.48 to 0.91$)$ for high dose $(40 / 80 \mathrm{mg})$ simvastatin (table 5).

The time varying analysis showed that the reduction in risk of oesophageal cancer was apparent one to three years after starting statins and persisted during the first five years of treatment. In women the risk returned to normal within the first year after stopping treatment and in men one to three years after stopping treatment.

\section{Acute renal failure}

The risk of acute renal failure was increased in both men and women prescribed simvastatin, atorvastatin, and pravastatin (table 4) and in women prescribed fluvastatin. The magnitudes of the adjusted hazard ratios were similar for each statin, ranging from 1.50 to 2.19 , and direct comparisons showed no difference in risk by type of statin $(\mathrm{P}=0.91$ in men, $\mathrm{P}=0.37$ in women). Too few patients were prescribed rosuvastatin to draw firm conclusions.

Evidence suggested a dose-response effect (table 5). For example, for women prescribed simvastatin 10/ $20 \mathrm{mg}$ the adjusted hazard ratio was 1.38 (1.10 to 1.74) and for simvastatin $40 / 80 \mathrm{mg}$ was 1.75 (1.32 to 2.32). For men the corresponding values were 1.39 (1.14 to 1.70 ) and 2.02 (1.63 to 2.52 ).

The increased risk of acute renal failure was apparent within the first year of starting treatment (adjusted hazard ratios 1.54 (1.09 to 2.17) for women and 1.67 (1.26 to 2.21) for men), and persisted for the first five years of treatment. The risk remained increased during the first year of stopping treatment and then returned to normal 1-3 years after stopping treatment: adjusted hazard ratios $1.23(0.69$ to 2.20$)$ for women and 1.57 (0.95 to 2.60) for men.

\section{Case series analysis}

As in the cohort analysis the case series analysis for moderate or serious myopathy showed increased risks during statin use compared with no use, although the magnitude of incidence rate ratios was larger than that in the cohort analysis but also had wide confidence intervals (table 6). The incidence rate ratios tended to be smaller but still significant when the case series analysis was restricted to new users and the observation 
period started at first use - for example, the rate ratio for simvastatin was 8.59 (95\% confidence interval 5.2 to 14.19$)$ and for atorvastatin was 4.37 (2.27 to 8.44$)$. The rate ratio for pravastatin was higher $(33.89,3.87$ to 297.14). Data for fluvastatin and rosuvastatin were insufficient for this analysis.

The case series analysis confirmed the significantly increased risk of cataract during the period of use of each statin compared with the period of non-use, except for pravastatin: adjusted incidence rate ratio 1.13 (95\% confidence interval 0.92 to 1.40$)$. The risk of acute renal failure was increased during simvastatin use $(1.57,1.27$ to 1.95$)$ and also rosuvastatin use (5.11, 1.05 to 24.92) compared with non-use. The increased risk of moderate or serious liver dysfunction during statin use compared with the period of non-use showed a similar pattern and magnitude to the cohort analyses.

Numbers needed to treat and numbers needed to harm Table 7 shows the NNTs and NNHs for each outcome among patients aged 35-74 who were at high risk of cardiovascular disease, as defined by two thresholds $(\geq 20 \%$ and $\geq 15 \%)$ for cardiovascular risk based on the QRISK2 10 year cardiovascular risk score.

Using the 20\% threshold in women, the NNT with any statin to prevent one case of cardiovascular disease over five years was 37 (95\% confidence interval 27 to 64 ) and for oesophageal cancer was 1266 (850 to 3460). For men, the corresponding values were 33 (24 to 57 ) and 1082 (711 to 2807).

In women, the $\mathrm{NNH}$ for an additional case of acute renal failure over five years was 434 (284 to 783), for moderate or severe myopathy was 259 (186 to 375), for moderate or severe liver dysfunction was 136 (109 to 175), and for cataract was 33 (28 to 38).

Overall, using the $20 \%$ threshold, the NNH or NNTs for men were similar to those for women except for myopathy where the NNH was 91 (74 to 112). This is lower than in women, mainly due to the higher hazard ratio in men.

Table 7 also shows the NNH or NNT for men and women selected using the $15 \%$ threshold for QRISK2 score. The event rates for each outcome in non-users of statins tended to be lower than when using the $20 \%$ threshold. The effect of this was to increase both the NNT and the NNH for each outcome. Table 7 also shows the estimated numbers of extra cases or cases prevented per 10000 people treated with statins at both thresholds. For example, using the $20 \%$ threshold there would be 271 fewer cases (95\% confidence interval 157 to 374 ) of cardiovascular disease for every 10000 women compared with 228 fewer cases (132 to 315 ) using the $15 \%$ threshold.

\section{DISCUSSION}

We examined and quantified the unintended risks and benefits of statins in a large representative primary care population over a six year period. Our study has good face validity because it was carried out in a setting where most patients in the United Kingdom are assessed, treated, and followed up. We were unable to confirm some potential unintended effects of statins, such as a protective effect on risk of Parkinson's disease, venous thromboembolism, ${ }^{18}$ rheumatoid arthritis, ${ }^{19}$ osteoporotic fracture,${ }^{2546}$ and dementia. ${ }^{15} 16$ This may be because compared with most previous studies our study was larger, prospective, and included more potential confounders.

Our findings largely confirm other studies that reported no clear association between statins and risk of cancers. ${ }^{92123478}$ There were two potential exceptions: oesophageal cancer, where we found a decreased risk, and colon cancer where there was an apparent decreased risk in men prescribed pravastatin and an increased risk in men prescribed rosuvastatin. These findings could represent a genuine association or could be due to chance, given the large number of outcomes under consideration in this study. Previous studies have not distinguished between the type of statin and specific cancer to this degree ${ }^{92123}$ or undertaken individual patient level analyses. Some of the older meta-analyses did not include rosuvastatin, which has been licensed relatively recently. Further studies using independent datasets should be undertaken to confirm or refute these findings, particularly as the use of statins is likely to increase.

We were able to quantify adverse effects associated with statins, including myopathy, liver dysfunction, acute renal failure, and cataract. These seem to be class effects, with a dose-response effect apparent for acute renal failure and liver dysfunction consistent with that reported elsewhere. ${ }^{928}$ We found a suggestion of a dose-response for myopathy among men prescribed pravastatin and atorvastatin, although the confidence intervals were wide owing to small numbers. As in previous studies, we found that adverse effects tended to be similar across the types of statins for most outcomes except for liver dysfunction, where the highest risks were associated with fluvastatin. All risks persisted during treatment and were highest in the first year of treatment. After stopping treatment the risk of cataract returned to normal within a year in men and women. Risk of oesophageal cancer returned to normal within a year in women and within 1-3 years in men. Risk of acute renal failure returned to normal within 1-3 years in men and women, and liver dysfunction within 1-3 years in women and from three years in men.

\section{Comparison with other studies}

Clinical trials and their associated meta-analyses provide valuable information on the effectiveness and efficacy of drugs. They are, however, limited in providing information on adverse events since such data are not always recorded or reported in a consistent fashion. Trials tend to be of short duration, under-powered for the detection of adverse events, and susceptible to selection bias, with participants tending to be predominantly white, younger, and healthier than the general population. Most statin trials and meta-analyses are designed to investigate the effectiveness of statins 


\section{WHAT IS ALREADY KNOWN ON THIS TOPIC}

Meta-analyses suggest that statins reduce the risk of cardiovascular disease, particularly in high risk patients

Although meta-analyses provide valuable information on effectiveness they tend to lack representative samples, duration of follow-up, or power to assess unintended effects

Information on the unintended effects of statins in representative primary care populations is lacking although statins are prescribed in large volumes for long periods

\section{WHAT THIS STUDY ADDS}

Individual statins were not significantly associated with risk of Parkinson's disease, rheumatoid arthritis, venous thromboembolism, dementia, osteoporotic fracture, and several common cancers

The risk of oesophageal cancer was reduced but for liver dysfunction, acute renal failure, myopathy, and cataract it was increased

Adverse effects were similar across the statin types for each outcome except liver dysfunction where fluvastatin was associated with the highest risks

compared with placebo. ${ }^{2} \mathrm{Few}$ are specifically designed to investigate adverse events. ${ }^{5}$

One systematic overview of 35 randomised trials quantified the musculoskeletal, renal, and hepatic effects associated with statin use. This study of 74102 predominantly white patients, with a mean follow up of 17 months, reported a small excess risk of increases in transaminase concentrations but no increase in risk of myalgias, increased creatine kinase concentrations, or rhabdomyolysis from statin use compared with placebo. ${ }^{8}$ The researchers concluded that further study is necessary to determine how their results compare with what occurs in routine practice, particularly among patients who are older, have more severe comorbid conditions, or receive higher statin doses than most patients in these clinical trials. ${ }^{8}$

Cholesterol Treatment Trialist Collaborators similarly reported another large meta-analysis of statin trials and reported no increased risk of cancer and a low excess risk of rhabdomyolysis, with a $0.01 \%$ excess risk over five years. ${ }^{3}$ They did not include liver dysfunction among the adverse outcomes, and other studies where this outcome has been reported have tended to be small. ${ }^{49}$

One observational study examined the comparative safety of individual statins for selected outcomes, including myopathy, acute renal failure, and acute liver injury. This study used the general practice research database and involved 100000 statin users followed for under three years. ${ }^{50}$ Our study adds to this trial by examining a larger population of statin users as well as including non-users, additional outcomes, and a longer duration of follow up. There are two main differences between our study and the general practice research database study. Firstly, we compared new users of statins with non-users whereas the general practice research database study was designed to compare different types of statins directly and did not include a non-user group. Secondly, we used more inclusive outcome definitions and identified many more cases. In the general practice research database study, in order for patients to be included as cases they needed both a computer recorded code of the outcome (for example, acute renal failure) and a computer code indicating admission to hospital, and if only one criterion was met the patient was not identified as a case. In our study we assumed that most patients with, for example, acute renal failure would be admitted to hospital and that the general practitioner would record the diagnostic code rather than the hospital admission itself.

\section{Methodological considerations}

Observational studies, with their large representative and ethnically diverse populations and their potential for longer term follow-up, have limitations, notably bias and unmeasured confounding. Recall bias is not of concern here because information on statin use was prospectively recorded on computer before the outcomes. Misclassification bias of use - that is, statin prescriptions - is possible because low dose simvastatin became available over the counter in August 2004. However, it is likely that most prescriptions are issued in primary care and recorded electronically, especially among elderly people and those with comorbidities, who will have free prescriptions. Any misclassification of statin use (or outcome) if non-differential, would tend to bias the hazard ratios towards 1 thus under-estimating a potential association. Misclassification of outcome is possible, although validation studies undertaken on similar general practice databases relating to similar outcomes where the general practitioner has been contacted for further detail have shown good results. ${ }^{1950}$

Ascertainment bias could occur as people starting statins tend to have more blood tests than those not starting statins thereby increasing the likelihood of detection of abnormal liver function tests or myopathy associated with a raised creatine kinase concentration. None the less, our study confirms the results of other studies that statins are associated with liver dysfunction ${ }^{817}$ and gives information on the likely volumes of affected people who need careful follow up. This not only has planning implications for general practitioner workload but may cause anxiety for patients. Our analysis, however, suggests that the risk of abnormal liver function tests is dose dependent and that it can be reversed on stopping treatment, both of which could help guide therapy and reassure people. Ascertainment or recording bias might also partly account for the increased risk of cataract because people prescribed statins may consult their general practitioner more often than the general population thereby increasing the opportunity for people to report on visual problems and be examined. ${ }^{51}$

Indication bias is particularly important for intended outcomes such as the reduction in risk of cardiovascular disease. Initially, we carried out an additional preliminary analysis using the prior event rate ratios approach $^{52}$ and obtained similar point estimates to those from the published meta-analyses. However, the prior event rate ratios approach is not valid for 
analyses of first events and cannot be applied if a diagnosis of an outcome before starting study drugs was an exclusion criterion. ${ }^{52}$ We have therefore used odds ratios $^{2}$ derived from meta-analyses to work out the numbers needed to treat at population level for cardiovascular disease, combined with event rates from QResearch.

Our case series analysis generally confirms the results of our main cohort analyses. It removes the effects of fixed cofounders and largely removes the effect of indication bias, although it could still be susceptible to ascertainment bias.

\section{Clinical implications}

At national level, our study is likely to be useful for policy and planning purposes because we have given the expected numbers of additional adverse events per 10000 patients that would occur if all patients likely to be at high risk of cardiovascular disease were prescribed statins, assuming the associations we found are causal. We undertook our analyses for $\mathrm{NNHs}$ and NNTs at two thresholds of cardiovascular risk $\geq 15 \%$ and $\geq 20 \%$ ) and showed that the potential benefits and harms both tend to increase as the threshold for intervention increases.

Our study may also be useful for informing guidelines on the type and dose of statins. Although adverse outcomes tended to be class effects overall with no significant differences between the statins, the risk of liver dysfunction was highest with fluvastatin. The risk of liver dysfunction, acute renal failure, and possibly myopathy were dose related and, as liver dysfunction is common and the other two outcomes potentially life threatening, the findings would tend to support a policy of using lower doses of statins in people at high risk of the adverse event.

While we have shown adverse associations between statin use and four outcomes and one protective association, our study was not designed to show causality. Although we have shown some evidence of doseresponse relations and reversibility (in that risk for most outcomes decreases on stopping treatment), consideration of potential biological mechanisms is outside the scope of this study.

\section{Conclusions}

In summary, we have reported a detailed epidemiological analysis of the unintended effects of statins in a large representative primary care population for a range of outcomes by type of statin, dose, and duration of use. We have given estimates on the number of additional events potentially caused or prevented per 10000 patients treated. The current paper quantifies risks and benefits of statins at population level, but the underlying algorithms also can be applied at the individual level. In a companion paper, ${ }^{53}$ therefore, we validate the algorithms at individual level so that they can be used to explain absolute and relative risks and benefits for an individual patient as well as to identify those at high risk of adverse events from statins for more proactive monitoring.
We thank the contribution of practices using the Egton Medical Information System (EMIS) who provide data to QResearch and to David Stables (medical director, EMIS) for his expertise in establishing, developing, and supporting the database and to ClinRisk who undertook the study

Contributors: $\mathrm{JH}-\mathrm{C}$ initiated the study, reviewed the literature, extracted and manipulated the data, carried out the primary data analysis, and wrote the first draft of the paper. CC contributed to the design, analysis, interpretation, and drafting of the paper. Both authors are guarantors.

Funding: No external funding.

Competing interests: $\mathrm{JH}-\mathrm{C}$ is codirector of QResearch (a not for profit organisation that is a joint partnership between the University of Nottingham and EMIS, the leading commercial supplier of IT for $60 \%$ of general practices in the United Kingdom) and director of ClinRisk, which produces software to ensure the reliable and updatable implementation of clinical risk algorithms within clinical computer systems to improve patient care. CC is a consultant statistician for ClinRisk. This work and any views expressed within it are solely those of the authors and not of any affiliated bodies or organisations.

Ethical approval: This study was independently reviewed in accordance with the QResearch agreement with Trent research ethics committee. Data sharing: The patient level data from the QResearch are specifically licensed according to its governance framework. See www.qresearch.org for further details. The Read codes groups used are available from the authors on request.

1 British Heart Foundation. Coronary heart disease statistics. BHF, 2007.

2 Brugts JJ, Yetgin T, Hoeks SE, Gotto AM, Shepherd J, Westendorp RG], et al. The benefits of statins in people without established cardiovascular disease but with cardiovascular risk factors: metaanalysis of randomised controlled trials. BMJ 2009;338:b2376.

3 Cholesterol Treatment Trialist Collaborators. Efficacy and safety of cholesterol-lowering treatment: prospective meta-analysis of data from 90,056 participants in 14 randomised trials of statins. Lancet 2005;366:1267-78.

4 Department of Health. Putting prevention first-vascular checks: risk assessment and management. 2008. www.dh.gov.uk/en/ Publicationsandstatistics/Publications/ PublicationsPolicyAndGuidance/DH_083822.

5 Thavendiranathan P, Bagai A, Brookhart MA, Choudhry NK. Primary prevention of cardiovascular diseases with statin therapy: a metaanalysis of randomized controlled trials. Arch Intern Med 2006;166:2307-13.

6 Hippisley-Cox J, Coupland C, Vinogradova Y, Robson J, Minhas R, Sheikh A, et al. Predicting cardiovascular risk in England and Wales: prospective derivation and validation of QRISK2. BMJ 2008;336;1475-82.

7 Jackson R, Marshall R, Kerr A, Riddell T, Wells S. QRISK or Framingham for predicting cardiovascular risk? BMJ 2009;339:b2673.

8 Kashani A, Phillips CO, Foody JM, Wang Y, Mangalmurti S, Ko DT, et al. Risks associated with statin therapy: a systematic overview of randomized clinical trials. Circulation 2006;114:2788-97.

9 Alsheikh-Ali AA, Maddukuri PV, Han H, Karas RH. Effect of the magnitude of lipid lowering on risk of elevated liver enzymes, rhabdomyolysis, and cancer: insights from large randomized statin trials. J Am Coll Cardiol 2007;50:409-18.

10 Nichols G, Koro G. Does statin therapy initiation increase the risk for myopathy? An observational study of 32,225 diabetic and non diabetic patients. Clin Therap 2007;29:1761-70.

11 Andrade SE, Graham DJ, Staffa JA, Schech SD, Shatin D, La Grenade L, et al. Health plan administrative databases can efficiently identify serious myopathy and rhabdomyolysis. J Clin Epidemiol 2005;58:171-4.

12 Graham DJ, Staffa JA, Shatin D, Andrade SE, Schech SD, La Grenade L, et al. Incidence of hospitalized rhabdomyolysis in patients treated with lipid-lowering drugs. JAMA 2004;292:2585-90.

13 Thompson PD, Clarkson P, Karas RH. Statin-associated myopathy. IAMA 2003;289:1681-90.

14 Huang X, Chen H, Miller W, Mailman RB, Woodard JL, Chen PC, et al. Lower low-density lipoprotein cholesterol levels are associated with Parkinson's disease. Mov Disord 2007;22:377-81.

15 Jick H, Zornberg G, Jick S, Seshadri S, Drachman D. Statins and risk of dementia. Lancet 2000;356:1627-31.

16 Szwast SJ, Hendrie HC, Lane KA, Gao S, Taylor SE, Unverzagt F, et al. Association of statin use with cognitive decline in elderly African Americans. Neurology 2007;69:1873-80.

17 Maron DJ, Fazio S, Linton MF. Current perspectives on statins. Circulation 2000;101:207-13. 
18 Ray JG, Mamdani M, Tsuyuki RT, Anderson DR, Yeo EL, Laupacis A. Use of statins and the subsequent development of deep vein thrombosis. Arch Intern Med 2001;161:1405-10.

19 Jick SS, Choi H, Li L, McInnes IB, Sattar N. Hyperlipidemia, statin use and the risk of developing rheumatoid arthritis. Ann Rheum Dis 2009;68:546-51.

20 Klein BEK, Klein R, Lee KE, Grady LM. Statin use and incident nuclear cataract. JAMA 2006;295:2752-8.

21 Dale K, Coleman C, Hentyan N, Kluger J, White C. Statins and cancer risk-a meta-analysis. JAMA 2006;295:74-80.

22 Addeo R, Altucci L, Battista T, Bonapace IM, Cancemi M, Cicatiello L, et al. Stimulation of human breast cancer MCF-7 cells with estrogen prevents cell cycle arrest by HMG-CoA reductase inhibitors. Biochem Biophys Res Commun 1996;220:864-70.

23 Bonovas S, Filioussi K, Tsavaris N, Sitaras NM. Statins and cancer risk: a literature-based meta-analysis and meta-regression analysis of 35 randomized controlled trials. J Clin Oncol 2006;24:4808-17.

24 Newman TB, Hulley SB. Carcinogenicity of lipid-lowering drugs. JAMA 1996;275:55-60.

25 Meier CR, Schlienger RG, Kraenzlin ME, Schlegel B, Jick H. HMG-CoA reductase inhibitors and the risk of fractures. JAMA 2000;283:3205-10.

26 LaCroix AZ, Cauley JA, Pettinger M, Hsia J, Bauer DC, McGowan J, et al. Statin use, clinical fracture, and bone density in postmenopausal women: results from the Women's Health Initiative Observational Study. Ann Intern Med 2003;139:97-104.

27 Cummings SR, Bauer DC. Do statins prevent both cardiovascular disease and fracture? JAMA 2000;283:3255-7.

28 Wolfe SM. Dangers of rosuvastatin identified before and after FDA approval. Lancet 2004;363:2189-90.

29 Food and Drug Admininstration. Information for healthcare professionals: crestor (rosuvastatin calcium). FDA, 2005.

30 Shepherd J, Hunninghake DB, Stein EA, Kastelein JJP, Harris S, Pears J, et al. Safety of rosuvastatin. Am J Cardiol 2004;94:882-8.

31 National Institute for Health and Clinical Excellence. Clinical guideline 64. Lipid modification-cardiovascular risk assessment and the modification of blood lipids for the primary and secondary prevention of cardiovascular disease. NICE, 2008.

32 Thompson PD, Clarkson PM, Rosenson RS. An assessment of statin safety by muscle experts. Am / Cardiol 2006;97(suppl 1):69-76S.

33 Shalev V, Chodick G, Silber H, Kokia E, Jan J, Heymann AD. Continuation of statin treatment and all-cause mortality: a population-based cohort study. Arch Intern Med 2009;169:260-8.

34 Jones P, Kafonek S, Laurora I, Hunninghake D. Comparative dose efficacy study of atorvastatin versus simvastatin, pravastatin, lovastatin, and fluvastatin in patients with hypercholesterolaemia. The CURVES Study. Am J Cardiol 1998;81:582-7.

35 Schafer J, Graham J. Missing data: our view of the state of the art. Psychol Methods 2002;7:147-77.

36 Group TAM. Academic medicine: problems and solutions. BMJ 1989;298:573-9.
37 Steyerberg EW, van Veen M. Imputation is beneficial for handling missing data in predictive models. J Epidemiol Community Health 2007;60:979.

38 Moons KGM, Donders RART, Stijnen T, Harrell FJ. Using the outcome for imputation of missing predictor values was preferred. J Epidemiol Community Health 2006;59:1092-101.

39 Royston P, Ambler G, Sauerbrei W. The use of fractional polynomials to model continuous risk variables in epidemiology. Int J Epidemiol 1999;28:964-74.

40 Farrington P, Nash J, Miller E. Case series analysis of adverse reactions to vaccine: a comparative evaluation. Am J Epidemiol 1996;143:1165-73.

41 Whitaker $\mathrm{H}$. The self controlled case series method. BMJ 2008;337:a1069.

42 Douglas IJ, Smeeth L. Exposure to antipsychotics and risk of stroke: self controlled case series study. BM/ 2008;337:a1227.

43 Tata LJ, West J, Smith C, Farrington P, Card T, Smeeth L, et al. General population based study of the impact of tricyclic and selective serotonin reuptake inhibitor antidepressants on the risk of acute myocardial infarction. Heart 2005;91:465-71.

44 Whitaker HJ, Farrington CP, Spiessens B, Musonda P. Tutorial in biostatistics: the self-controlled case series method. Stat Med 2006;25:1768-97.

45 Altman DG, Andersen PK. Calculating the number needed to treat fo trials where the outcome is time to an event. BMJ 1999;319:1492-5.

46 Bauer DC, Mundy GR, Jamal SA, Black DM, Cauley JA, Ensrud KE, et al. Use of statins and fracture: results of 4 prospective studies and cumulative meta-analysis of observational studies and controlled trials. Arch Intern Med 2004;164:146-52.

47 Bonovas S, Nikolopoulos G, Filioussi K, Peponi E, Bagos P, Sitaras NM. Can statin therapy reduce the risk of melanoma? A metaanalysis of randomized controlled trials. Eur J Epidemio 2010;25:29-35.

48 Singh H, Mahmud SM, Turner D, Xue L, Demers AA, Bernstein CN Long-term use of statins and risk of colorectal cancer: a populationbased study. Am / Gastroenterol 2009;104:3015-23.

49 Tolman KG. The liver and lovastatin. Am J Cardiol 2002;89:1374-80

50 García-Rodríguez LA, Massó-González EL, Wallander M-A, lohansson S. The safety of rosuvastatin in comparison with other statins in over 100000 statin users in UK primary care. Pharmacoepidemiol Drug Saf 2008;17:943-52.

51 Smeeth L, Hubbard R, Fletcher AE. Cataract and the use of statins: a case-control study. Q J Med 2003;96:337-43.

52 Tannen RL, Weiner MG, Xie D. Use of primary care electronic medical record database in drug efficacy research on cardiovascular outcomes: comparison of database and randomised controlled trial findings. BMJ 2009;338:b81.

53 Hippisley-Cox J, Coupland C. Individualising the risks of statins in men and women in England and Wales: population based cohor study using the QResearch database. Heart [forthcoming].

Accepted: 2 March 2010 